\title{
REVIEW
}

\section{Hypotheses for the decline of cod in the North Atlantic*}

\author{
Ransom A. Myers ${ }^{1, * *}$, Jeffrey A. Hutchings ${ }^{2}$, N. J. Barrowman ${ }^{1}$ \\ ${ }^{1}$ Northwest Atlantic Fisheries Centre, Science Branch, PO Box 5667, St. John's, Newfoundland, Canada A1C 5X1 \\ ${ }^{2}$ Department of Biology, Dalhousie University, Halifax, Nova Scotia, Canada B3H 4J1
}

\begin{abstract}
We examine alternative hypotheses for the decline of $20 \mathrm{cod}$ Gadus morhua stocks in the North Atlantic. The year of the lowest observed biomass of spawners did not correspond to low juvenile survival for the cohorts that should have contributed to the stock in that year. However, fishing mortality was very high for the years preceding the collapse. The collapse of the cod stocks was not caused by a lack of resilience at low population abundance because all spawners were able to produce many potential replacements at low population size. We show that as populations collapsed, fishing mortality increased untıl the populations were reduced to very low levels. We conclude that increased fishing mortality caused the population declines, and often the collapses, of the cod stocks.
\end{abstract}

KEY WORDS: Gadus morhua Cod North Atlantic Decline - Stocks - Time series - Spawners . Recruitment Catch-Mortality Collapse Density-dependent mortality-Fishing

\section{INTRODUCTION}

During the last few years many of the world's cod Gadus morhua stocks have rapidly declined to the point where fishing has been effectively eliminated. This has caused a major economic and social disaster for some regions. By 1993, 6 Canadian stocks of cod had collapsed to the point where a total moratorium was declared on fishing (Hutchings \& Myers 1994). In 1994, Iceland, which depended on cod for $70 \%$ of its export earning, reduced its cod catches by $1 / 2$ in 1 yr. Similar drastic reductions occurred in Norway in 1989 (Jakøbsen 1994). The cod populations off the eastern USA are at unprecedented low levels (Murawski et al. 1996). Reductions in catch have occurred or are contemplated in other regions (ICES 1994a). The purpose of this paper is to investigate the causes of these collapses.

In an analysis of small pelagic fish, Beverton (1990) posed 5 fundamental questions about the collapse of

\footnotetext{
- Dedicated to the memory of the late R. J. H. Beverton, whose work inspired this paper

-E-mail: myers@mrspock.nwafc.nf.ca
}

a fishery. We have reformulated these questions as follows:

(1) What was the extent and timing of the population decline?

(2) To what extent were increased juvenile and fishing mortality responsible for the population decline?

(3) How resistant was the population to increased fishing through compensation in recruitment?

(4) What is the resilience of the population, i.e. its ability to reproduce and grow at low population sizes?

(5) Do catchability, spatial distribution, and fishing mortality change at low population sizes?

We address these questions using methods similar to those employed by Beverton (1990). We differ from Beverton in that we believe that it is important to separate juvenile mortality into natural mortality and that indirectly caused by fishing, e.g. discarding of young fish. In addition, we ask:

(6) How did the perception of fishing mortality change over time?

(7) How does the collapse of cod compare with the collapse of small pelagic fish examined by Beverton? 


\section{TESTING HYPOTHESES}

We first consider the timing and cause of the decline in the cod stocks. We use the Spawning Stock Biomass (SSB) as our metric of the stock status, which is denoted in year $y$ as $S$, and is defined as

$$
S_{y}=\sum_{a=1}^{A} N_{y, a} W_{y, a} P_{w, a}
$$

where $A$ is the maximum age observed, $w_{y, a}$ is the weight at age a at the time of spawning in year $y_{1} N_{y}$ a is the numbers of fish alive at the time of spawning in year $y$ at age $a$, and $P_{y, a}$ is the proportion mature at age a in year $y$.

If environmental change in early life is the primary cause of population declines, we would expect to see a decline in the survival to recruitment. If $y_{\mathrm{mm}}$ is the year of minimum SSB, then we would expect survival of the year classes that should have contributed to the SSB in
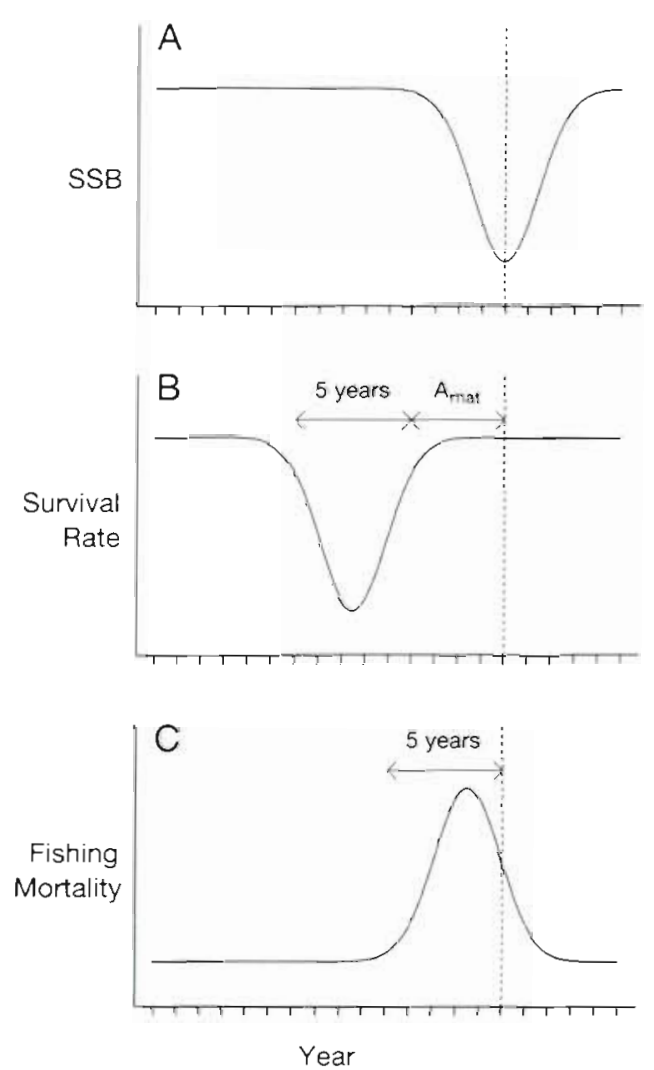

Fig. 1. Expected pattern in the change of (A) Spawning Stock Biomass (SSB), (B) standardized juvenile survival rate, and (C) fishing mortality under alternative hypotheses. If the $\mathrm{min}$ imum SSB was caused by decreased juvenile survival for the 5 yr that should have most contributed to the SSB (i.e. the $5 \mathrm{yr}$ previous to the number of years required for maturity, $A_{\text {max }}$ ), then we should expect juvenile survival as in (B). If the minimum SSB was caused by an increased fishing mortality in the 5 yr before the minimum, then we should expect the pattern of fishing mortality in (C) that year to be low if this hypothesis is true (Fig 1). The last 5 year classes that contributed to the SSB in the year of SSB minimum are

$$
y_{\text {min }}-A_{\text {ridi, }}, \ldots, y_{\text {min }}-A_{\text {mat }}-4
$$

where $A_{\text {mat }}$ is the average age at which $50 \%$ of females are mature. The average of the juvenile survival over these 5 yr represents the survival of those recruits that contributed to the minimum SSB. The juvenile survival that contributed to the maximum SSB was computed in a similar way (Table 1). The choice of 5 yr makes our analysis comparable to that of Beverton (1990).

Juvenile survival rate is the ratio of the number of recruits to the SSB of the parent stock. The juvenile survival rate (termed reproductive rate by Beverton 1990 ) is estimated from egg production to recruitment to the fishery. This index of 'juvenile' survival will include the egg and larval stage as well as the early demersai stage up to the age that fishing begins. For northern regions, the age of recruitment to the fishery is $3 \mathrm{yr}$, e.g. the Barents Sea stock $\mathrm{k}_{\mathrm{i}}$ while in warmer waters, the age of recruitment is $1 \mathrm{yr}$, e.g. the Irish Sea stock. Using a scaling factor, the survival rate can be converted into a standardized form which allows survival rates to be compared across stocks. The scaling factor we use is $S P R_{F=0}$, the spawning stock biomass per recruit when fishing mortality is zero (Goodyear 1977, Gabriel et al. 1989, Mace \& Sissenwine 1993, Mace 1994), which is defined as

$$
\mathrm{SPR}_{F=0}=\sum_{d=a_{r}}^{A} w_{d} P_{d} \mathrm{e}^{-\sum_{c=1}^{a-1} M_{c}}
$$

where $a_{r}$ is the age of recruitment to the fishery and $M_{C}$ is natural mortality at age $c$. Thus, the standardized juvenile survival rate to recruitment is

$$
\frac{N_{y+a_{p} d_{r}}}{S_{Y}} \cdot \mathrm{SPR}_{F=0}
$$

Estimates of $S P R_{F=0}$ were extracted from the database compiled by Mace \& Sissenwine (1993) and are based on the same age-at-recruitment, growth, and maturation schedules used in the Myers et al. (1995c) database of spawner, recruitment, catch and fishing mortality estimates. Note that when the standardized juvenile survival rate is less than 1 , the population would not be expected to replace itself. We use the term 'survival rate' instead of the term 'reproductive rate' used by Beverton (1990) because Eqs. (3) and (4) measure survival to the commercial fishery, i.e. some of the mortality may be caused by discarding and not be related to reproductive success in the ordinary sense.

In several cases, the time series for recruitment and SSB extend back to the beginning of the large-scale industrial fishery (late 1950s/early 1960s), e.g. West Greenland, Labrador/NE Newfoundland, St. Pierre 


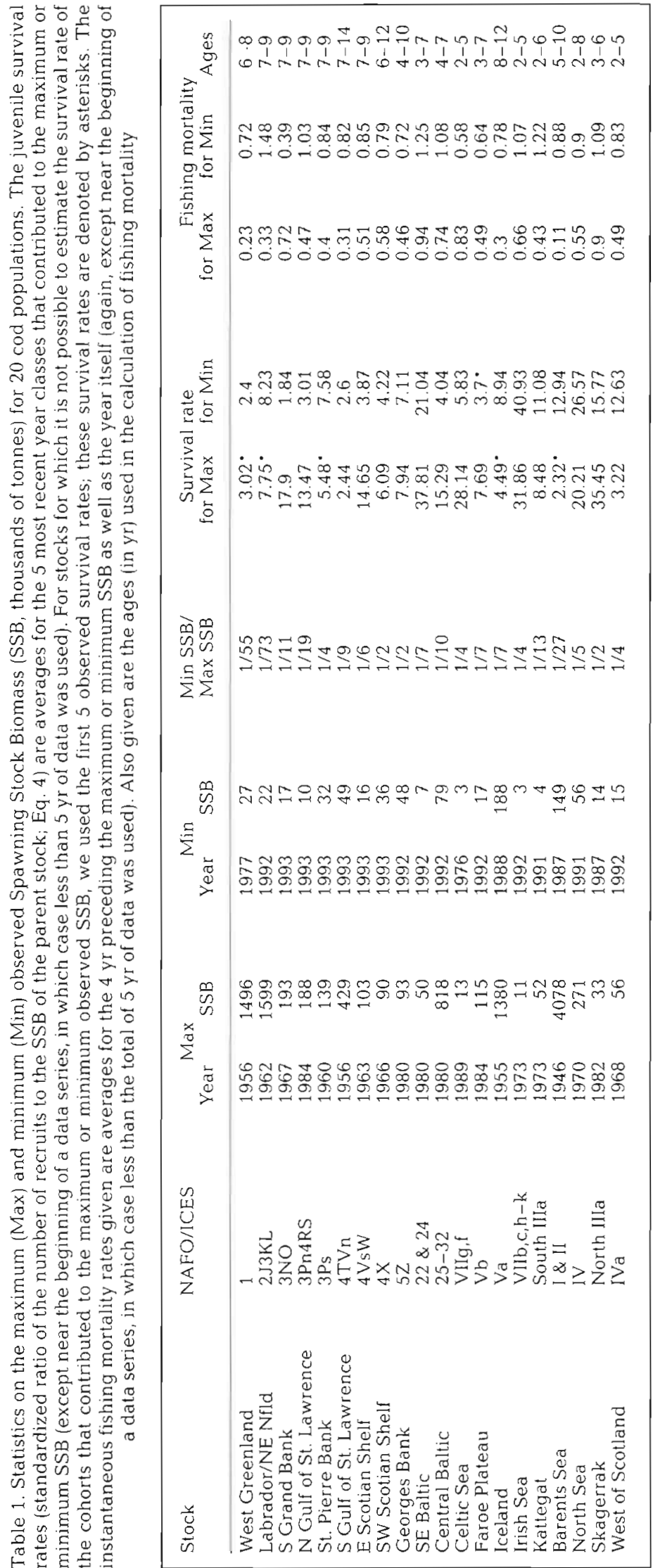

Bank, and the Barents Sea. For these stocks, it is not possible to estimate the juvenile survival of the cohorts that contributed to the maximum or minimum observed SSB because the recruitment estimates for these cohorts are not available; instead we used the first 5 observed survival rates. These survival rates are denoted by asterisks in Table 1. These should be typical of the survival rates when SSB is very large and should be adequate for our purposes.

If fishing mortality is the prime cause of fishery collapses, we would expect to see fishing mortality increase during the decline of the fishery. To examine the effect of fishing mortality, we compared the average fully recruited fishing mortality in the year of maximum SSB and the 4 preceding years with that of the year of minimum SSB and the 4 preceding years (Fig. 1, Table 1). Unfortunately, the data series did not always extend far enough back to allow all 5 yr to be used. In these cases, we used as many years of data as were available.

\section{What was the extent and timing of the population declines?}

Many of the cod stocks have declined enormously; the spawning biomass for the Labrador/NE Newfoundland stock was reduced to $1 / 73$ of its former value (Fig. 2, Table 1). Most of the stocks reached their minimum in the late 1980 s or early 1990s. One of the most striking aspects of the temporal trend in fishing mortality is the large increase in nearly all stocks since the 1970s. In the early 1990s, this increase generally coincided with the lowest observed levels of spawner biomass. Note that the reference fishing mortalities were rarely met, and there was great variability in the extent to which the observed SSB had changed over time.

\section{To what extent were increased juvenile and fishing mortality responsible for the population declines?}

\section{Hypothesis 1: The declines are caused by increased juvenile mortality}

A strong test of this hypothesis is to determine whether the standardized juvenile survival preceding the minimum was above 1 . In no case was the average standardized juvenile 

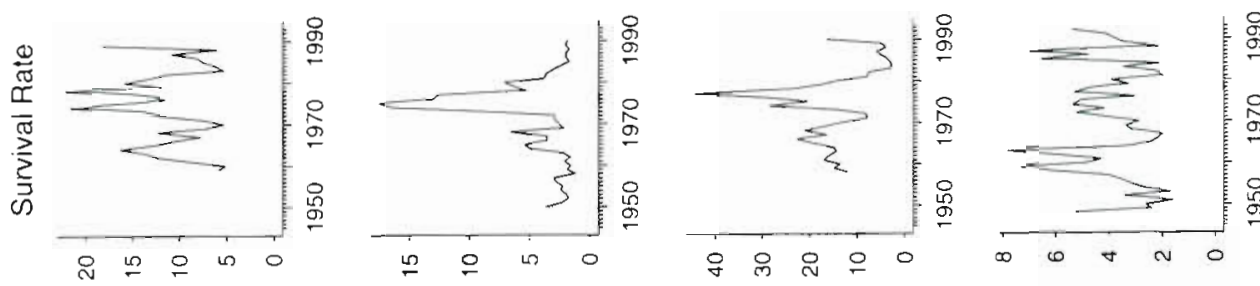

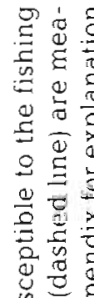

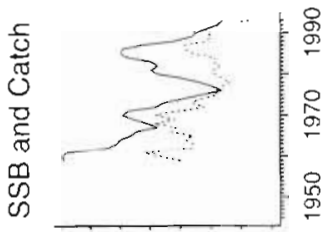

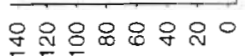

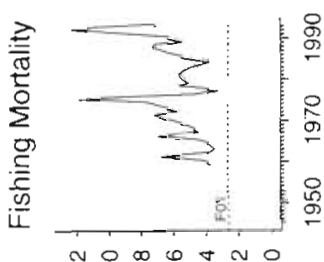

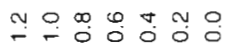

के

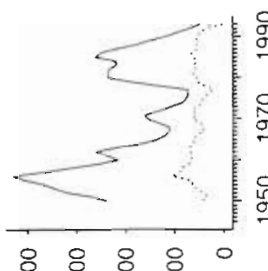

$8 \%$

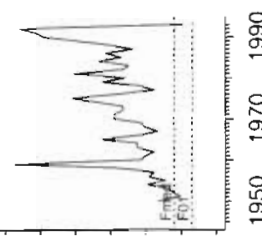

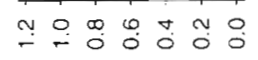

के के

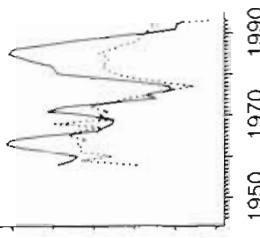

$8.88 \% 0$

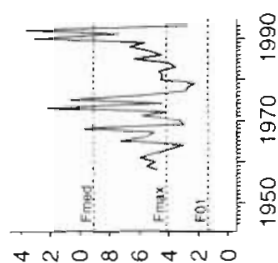

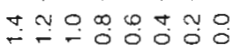

山.

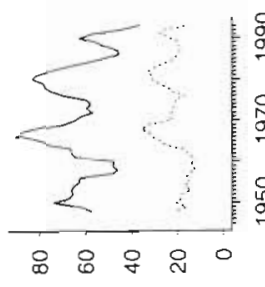

के

要要过

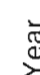

बे

空

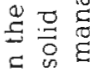

$\stackrel{0}{\circ}$

$\longrightarrow$ 丞 步宓

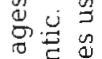

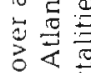

곤현

西安

焉

g. $\subseteq$

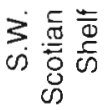

要

के is

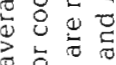

$\therefore 50$
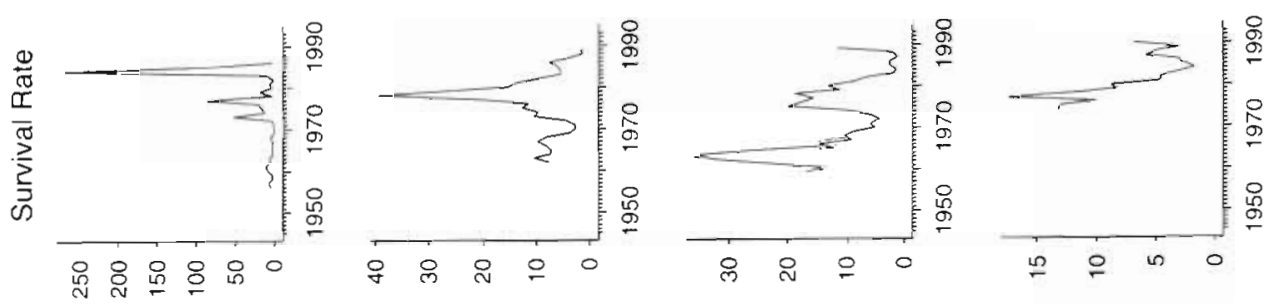

送遂

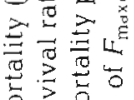

政

象号

至

․ㅡㅁ
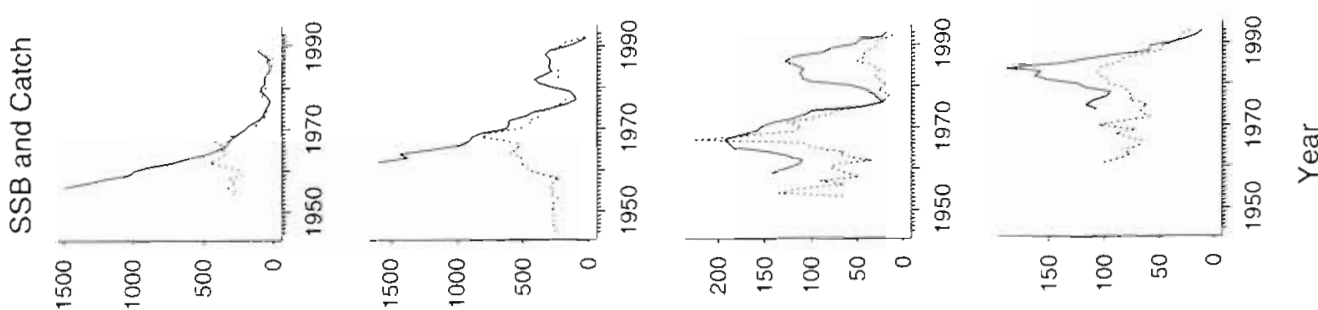

吾

递至象

娄要

落要

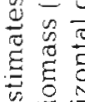

通率
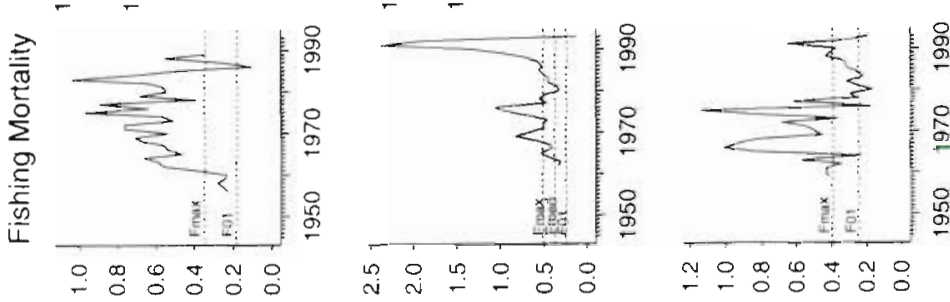

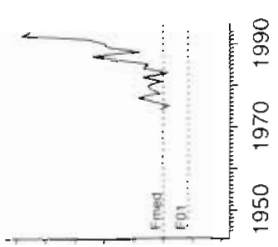

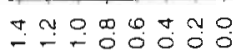

㝕宽

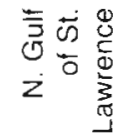



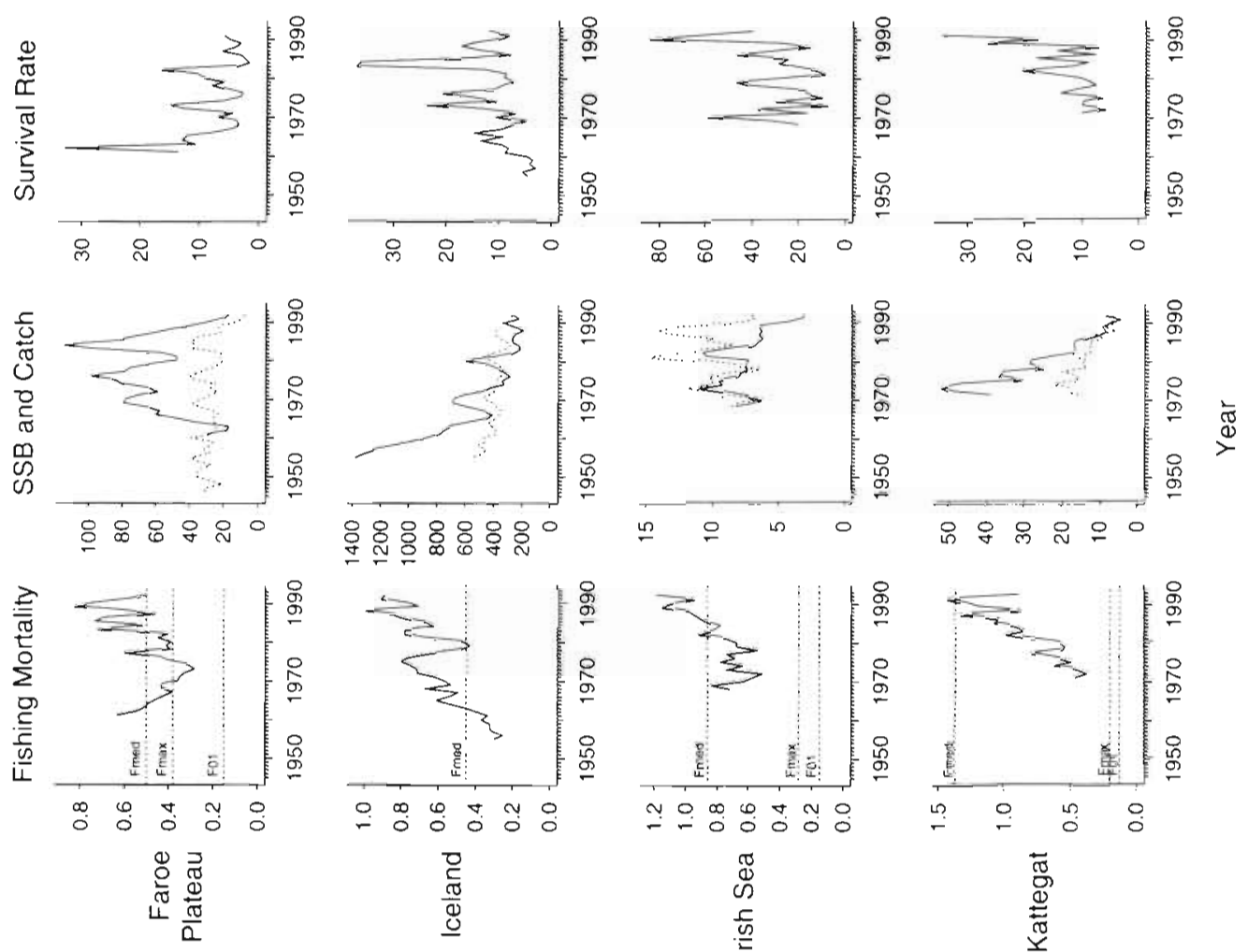

몸

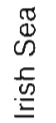

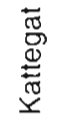
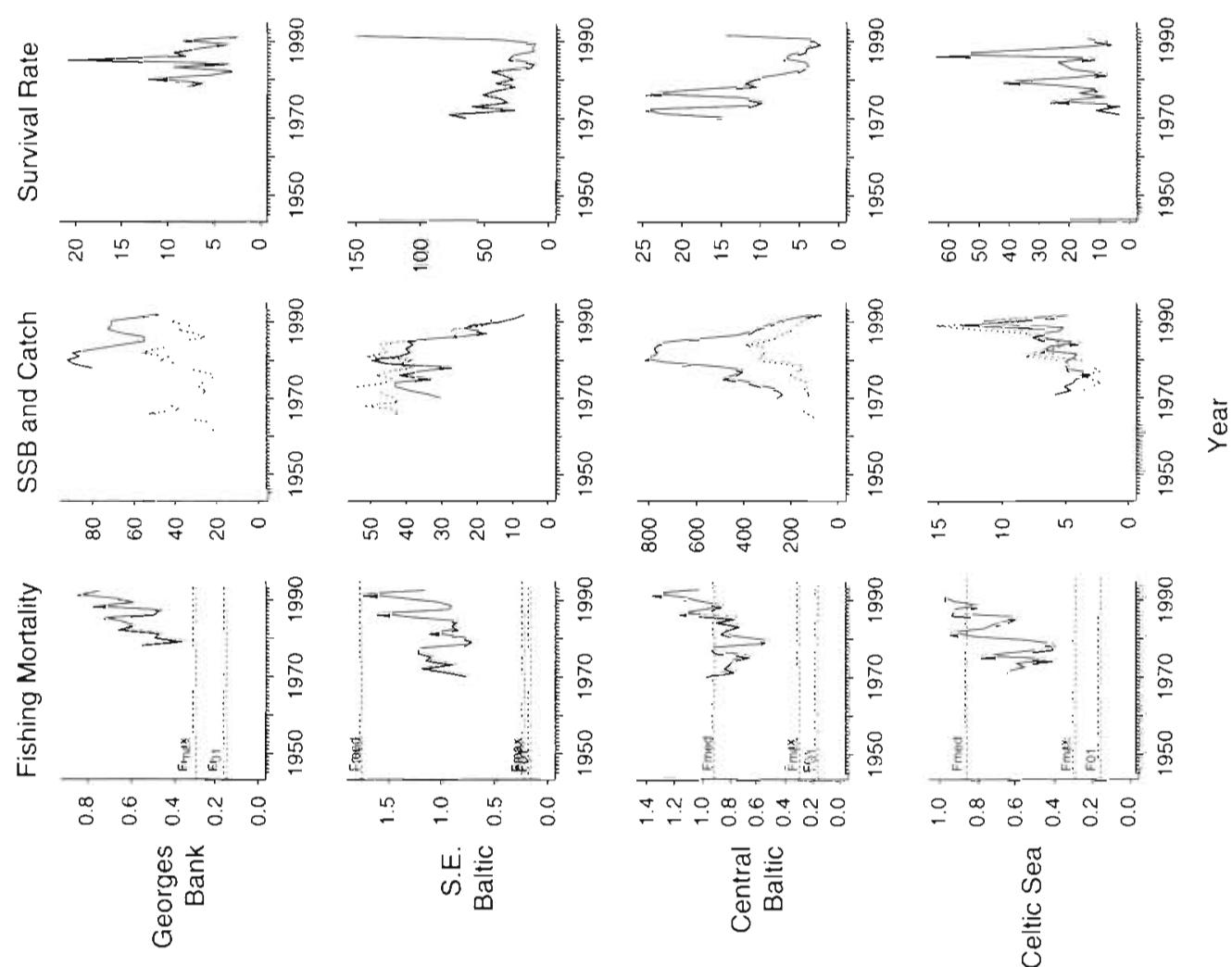

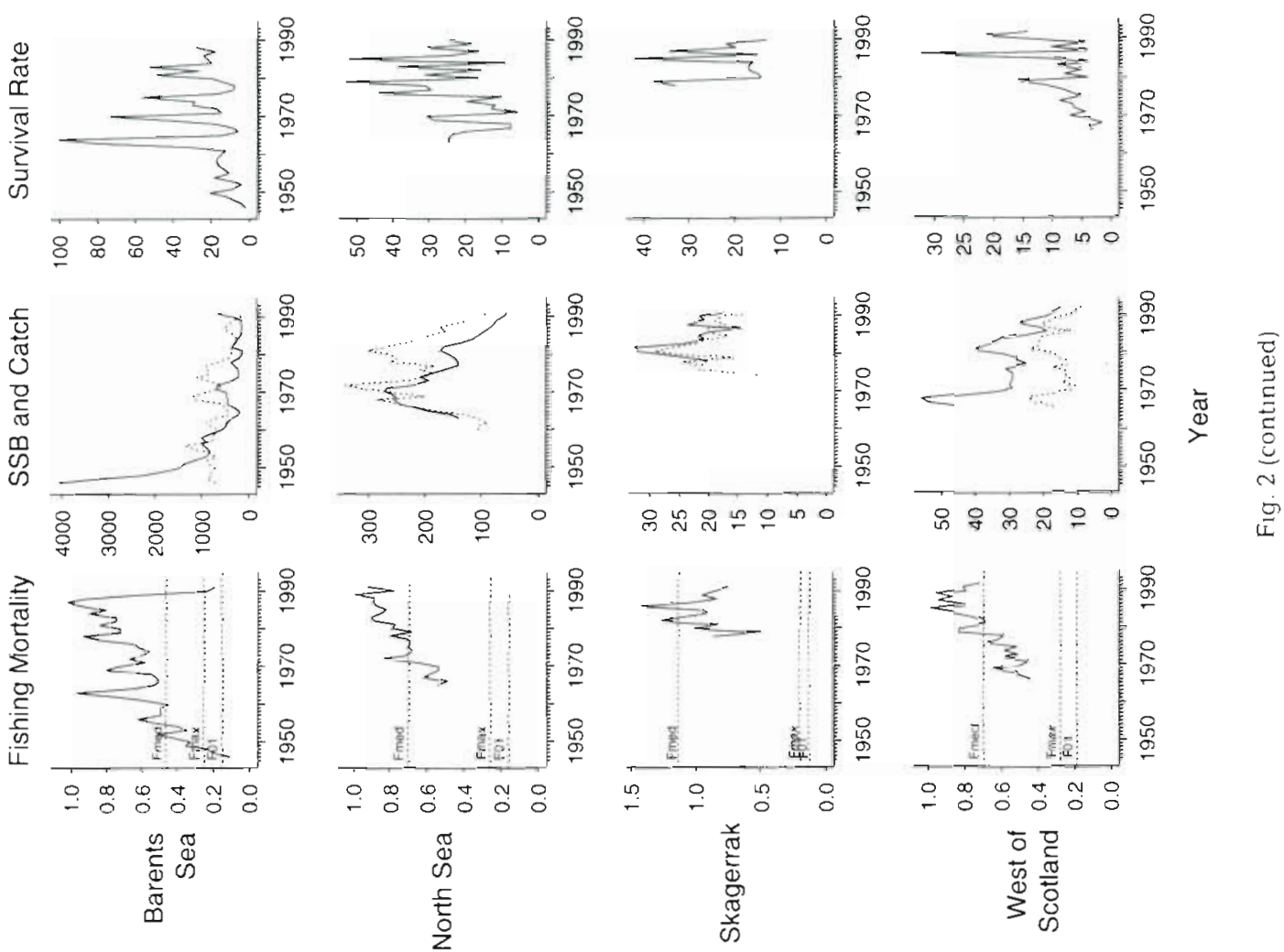

survival below 1 for the 5 most recent cohorts contributing to the minimum (Table 1, Fig. 2). That is, in the absence of fishing, all stocks should have grown during the years preceding the population minimum. If environmental conditions detrimental to juvenile survival were generally a major contributor to the declines, we would expect the survival rate preceding the minimum SSB to be less than that preceding the maximum SSB. However, there is no relationship between the ratio of the minimum SSB to the maximum SSB and the ratio of the survival rate preceding the minimum SSB to that preceding the maximum SSB (Fig. 3A). This result also holds if we only consider those stocks for which we have all years available to calculate juvenile survival. Furthermore, the number of stocks in which the ratio of survival rates is greater than 1 is almost equal to the number for which it is less than 1 (Fig 3A, Table 1). We conclude that changes in juvenile survival were not the cause, nor generally a major contributing factor, to the declines. For Labrador/NE Newfoundland cod, the highest juvenile survival ever observed, for the 1978 and 1979 cohorts, did not result in an increase in SSB when they reached maturity approximately 7 yr later. Mortality estimates from mark-recapture experiments indicate that these recruits suffered very high fishing mortality and very few survived to spawning age (Myers et al. 1996a, b). In the west of Scotland stock (IVa), a decline in SSB oc- curred in spite of a very large increase in juvenile survival. In this case, the decline was caused simply by an increase in fishing mortality over a 25 yr period (Fig. 2) In those stocks in which juvenile survival was reduced it was still high enough to allow the population to expand at low fishing levels, i.e. the standardized juvenile survival was greater than 1 (Table 1).

Although the hypothesis that population declines were primarily due to reduced juvenile survival can be rejected in general, there are 2 stocks for which the declines may be blamed in part on increased juvenile mortality: the Celtic Sea and the southern Grand Bank stocks. In each case, the survival rate was greatly reduced for the 5 cohorts that contributed to the minimum SSB, and the fishing mortality was less for these cohorts than for those at the maximum SSB. In the case of the southern Grand Bank stock, the increased juvenile mortality appears to be largely caused by fishing mortality on pre-recruits (Walsh et al. 1995).

Hypothesis 2: The declines are caused by increased fishing mortality

If fishing is the prime cause of the population declines, then greater fishing mortality should have occurred in the years before the minimum observed $\mathrm{SSB}$. Using this criterion, our data are clearly consis- 

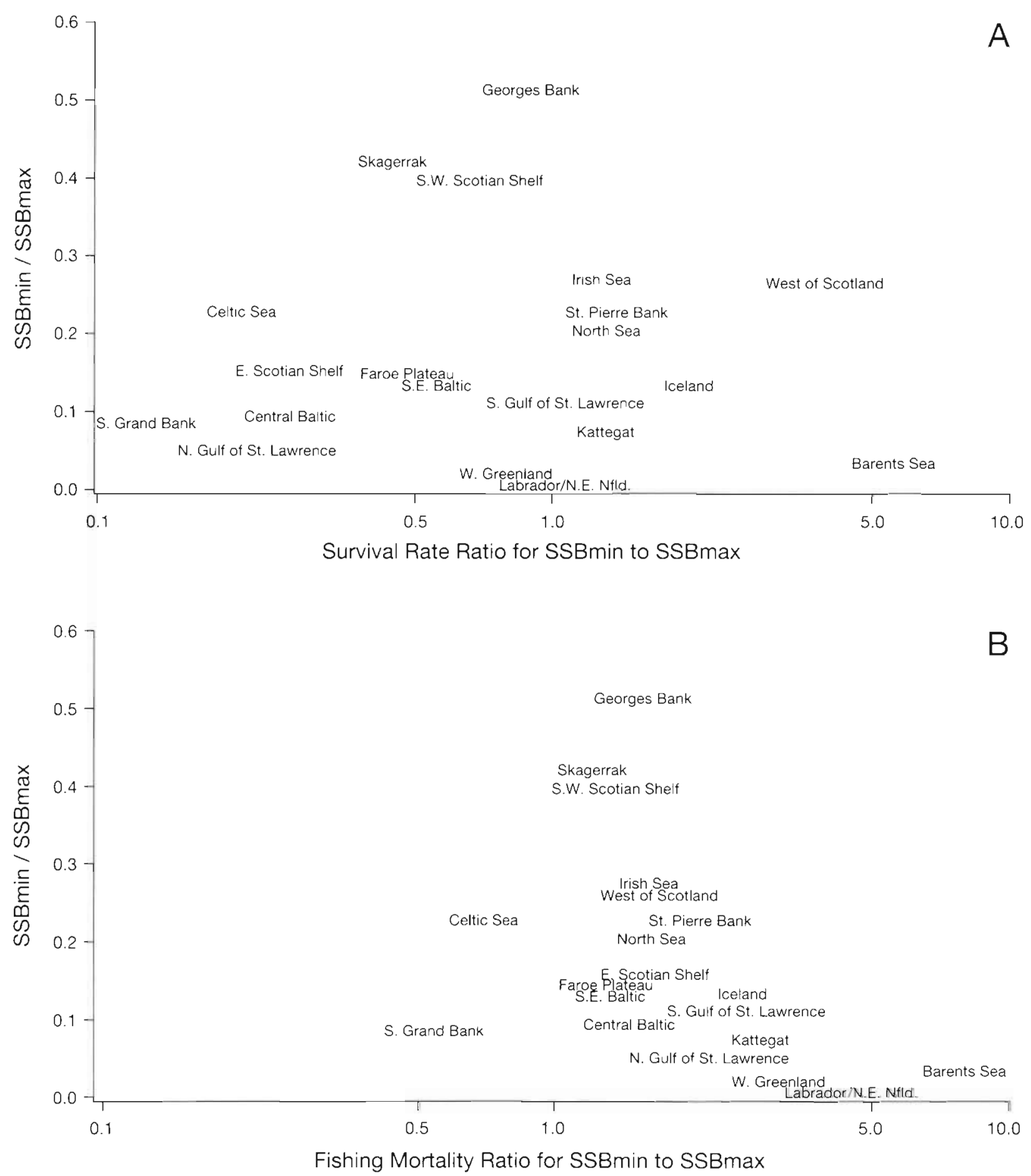

Fig. 3. Ratio of minimum Spawning Stock Biomass (SSB) to peak SSB vs (A) ratio of standardized juvenile survival that produced minimum SSB to juvenile survival that produced peak SSB, (B) ratio of average fishung mortality for the year of the minimum and the 4 yr prior to the minimum to average fishing mortality for the peak year and the 4 previous years. The values have been moved slightly so the stock names are readable

tent with the fishing mortality hypothesis because in only 2 cases was fishing mortality greater in the $4 \mathrm{yr}$ before the peak than in the 4 yr preceding the SSB minimum (Table 1, Fig. 3B). Furthermore, we would expect the highest fishing mortality to be associated with the greatest reductions in SSB. There is a significant negative relationship between the depth of the decline and the ratio of the fishing mortality preceding the maximum SSB to that preceding the minimum $\operatorname{SSB}(r=-0.47, p=0.039, n=20)$. 
For all the Canadian stocks (Labrador/NE Newfoundland, S Grand Bank, St. Pierre Bank, the north and south Gulf of St. Lawrence, E Scotian Shelf, SW Scotian Shelf), fishing mortality increased suddenly around 1989 to 1992 (Fig. 2). Instantaneous fishing mortality rate increased from approximately 0.5 in the mid 1980 s to above 1 for all stocks except southern Grand Bank. This drastic and sudden increase did not occur in ICES regulated stocks where fishing mortality gradually increased from the 1970 s until 1990

\section{Juvenile versus fishing mortality}

The decline, and often collapse, of the great cod fisheries of the world was caused by overfishing; increased fishing mortality and not increased juvenile mortality was associated with the minimum spawner biomass. It is unlikely that increased juvenile mortality was even a contributing factor for many stocks. The most dramatic collapse, that of Labrador/NE Newfoundland cod appears to be due almost entirely to overfishing because the survival rate of the cohorts that should have contributed to the SSB in the year of the collapse was almost equal to that for the period of peak biomass. Even very good recruitment cannot prevent a population collapse, e.g. cod in Georges Bank and the North Sea were greatly reduced even though the recruitment per spawner was very good.

If anything, our analysis underestimates the role of fishing because we have not included juvenile mortality caused by discarding of young fish that are caught but are not of marketable size (Myers et al. 1996c). Such mortality would appear in our analysis as interannual variability in survival because such fish would not be included in the data used to estimate mortality (data on discards are rarely included in the estimates of commercial catch-at-age). It appears that discarding mortality increased as Canadian cod populations declined (Myers et al. 1996c).

Cushing (1982), Dickson \& Brander (1993) and Mann \& Drinkwater (1994) have argued that climate often has a dominant influence over fishing mortality; however, there has been no attempt to quantify the effects of the climate versus the effects of the fishery. Even in the most convincing case for climatic control they examined, the role of the anoxia in the decline in recruitment rate of the Baltic cod stocks in the 1980s, there was also a large increase in fishing mortality (Fig. 2)

The almost simultaneous decline of many cod stocks has led many researchers to suggest that large-scale environmental changes must be the cause (ICES 1994a). However, earlier hypotheses that recruitment of marine fish in the North Atlantic is controlled by environmental factors that extend across the ocean basin (Templeman 1972, Garrod \& Colebrook 1978) were rejected when tested using $20 \mathrm{yr}$ of independent data by Myers et al. (1995b). The spatial scale of cod recruitment appears to be approximately $500 \mathrm{~km}$ (Myers et al. 1995a), which is too small to account for declines in cod stocks that have occurred over 1000 s of kilometers.

It has also been proposed that increased natural mortality in 1991 on adult cod was responsible for the collapse of the cod stocks in the Newfoundland region (Atkinson \& Bennett 1994). However, when the data that were used to generate this hypothesis, i.e. commercial catch-at-age and research survey data, were examined using statistical methods with correlated error structure (which is more realistic than the assumption that errors are independent), Myers \& Cadigan (1995a; b) found no statistically significant evidence for the hypothesis. Further evidence against the hypothesis was provided by Hutchings \& Myers (1994), who showed, using inshore and offshore catchper-unit effort data, that the decline in the cod stock did not occur suddenly in one year as required by the hypothesis that natural mortality suddenly increased.

We conclude that there is little evidence in support of the hypothesis that the influence of the environment on cod survival is dominant to that of fishing mortality.

\section{How resistant was the population to increased fishing through compensation in recruitment?}

A population is resistant to increased fishing if it can compensate for increased fishing mortality by increased density-dependent survival or growth. We estimate the limit of the rate at which spawners produce juveniles to replace themselves as the population is reduced to nearly zero. That is, we estimate the slope at the origin of the reproduction curve (Royama 1992) or the spawner-recruitment curve (Ricker 1954).

We consider the Ricker and Beverton-Holt spawnerrecruitment models which describe the number of recruits at age $a_{r}$ in year $y+a_{r}$ resulting from a SSB of $S_{y}$ (Fig 4). The Ricker model has the form

$$
E\left(N_{y+a_{i}, a_{r}}\right)=\alpha S_{y} \mathrm{e}^{-\beta S_{y}}
$$

and the Beverton-Holt model is

$$
E\left(N_{y+a_{r}, a_{f}}\right)=\frac{\alpha S_{y}}{1+\left(S_{y} / K\right)}
$$

where $E$ is expectation and $\alpha$ is the slope at the origin (measured perhaps in recruits per kilogram of spawners). In the Ricker model, density-dependent mortality is assumed to be the product of $\beta$ times the recruitment. For the Beverton-Holt model the parameter $K$ controls 

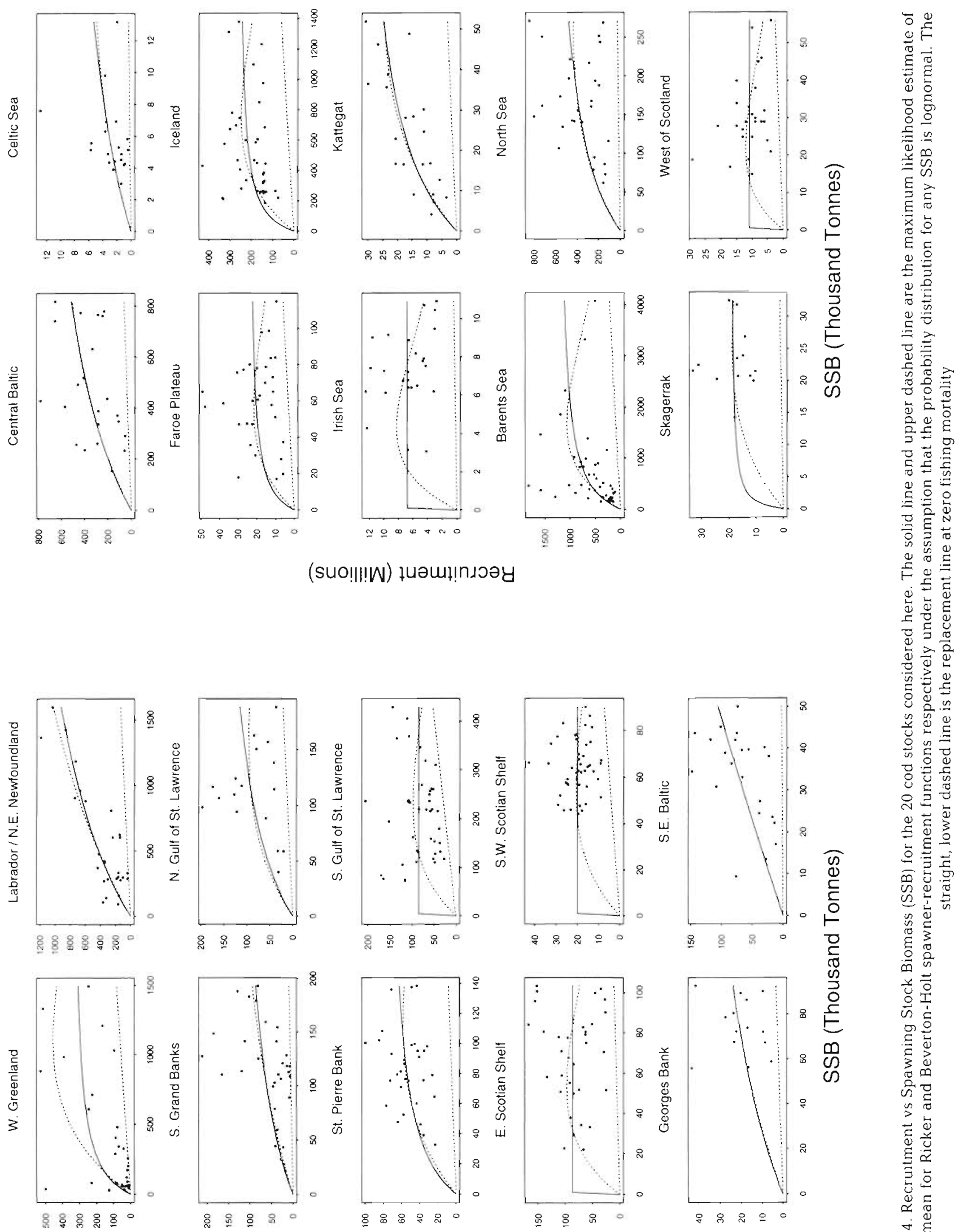

(suo!!!!W) †นәแ!!n^วәย

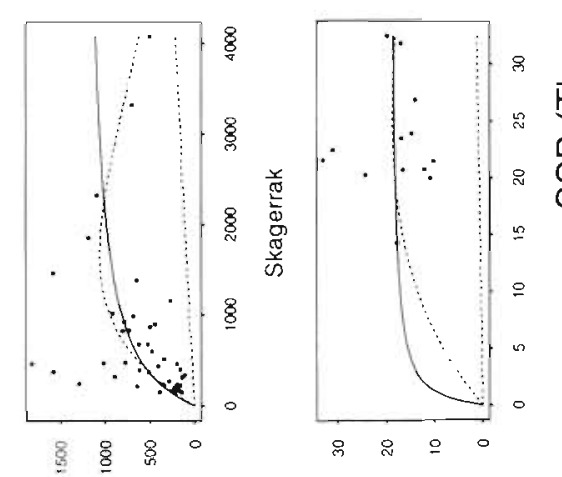


density-dependent mortality and has dimensions of biomass. The parameters were fit using maximum likelihood estimation and assuming lognormal variability in the deviations from the spawner recruitment function (Hilborn \& Walters 1992, Myers et al. 1995c).

The standardized initial slope, $\hat{\alpha}$, is obtained by scaling the initial slope $\alpha$ by $\mathrm{SPR}_{F=0}$, i.e.

$$
\hat{\alpha}=\alpha \cdot \mathrm{SPR}_{F=0}
$$

The standardized slope at the origin is our parametric measure of resilience; $\hat{\alpha}$ represents the number of spawners produced by each spawner over its lifetime at very low population sizes.

The estimates of the standardized slope at the origin for cod are much greater than 1 (Figs. $4 \& 5$ ). There are usually only moderate reductions of recruitment at lower stock sizes. The median estimate of $\hat{\alpha}$ is 21 for the Ricker model and 40 for the Beverton-Holt model. Although $\hat{\alpha}$ is not well estimated for some stocks because there are few or no observations near the origin, overall it is clear that each cod can generally be expected to produce approximately 30 replacements on average at low spawner biomass over the lifetime of a spawner.

The slope at the origin for the Ricker model is usually less than that estimated for the Beverton-Holt model (Fig. 4). The difference is caused by the different forms

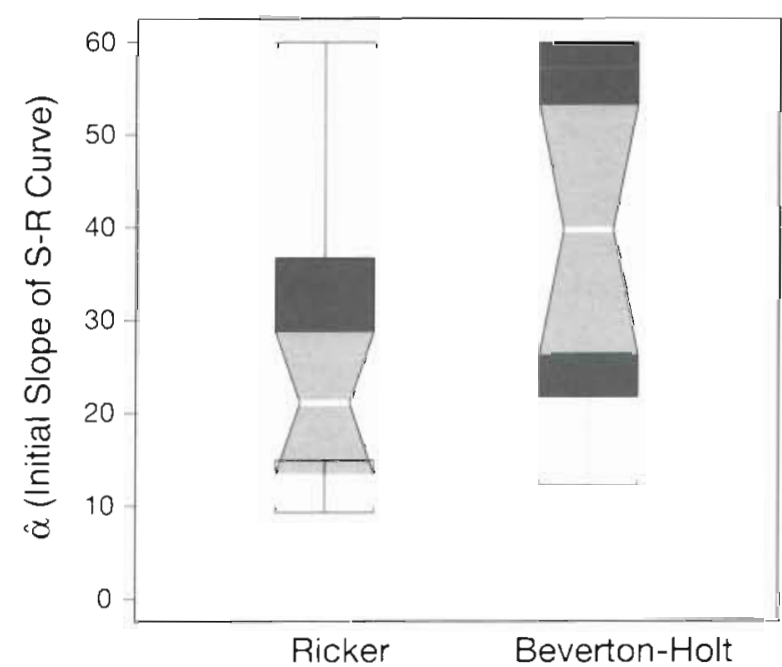

Fig. 5. Box and whisker plots (Hoaglin et al. 1983) of the standardized slope of the spawner-recrultment relationship at the origin, $\hat{\alpha}$. The width of each box is proportional to the square root of the number of data points. The white line in the middle of the box shows the median. The notch indicates the $95 \%$ confidence interval for the median. The outline of the box gives the upper and lower quartile. The whiskers are drawn to the nearest value not beyond $1.5 \times$ (inter-quartile range) from the quartiles. In order to eliminate unreasonably high estimates when there is insufficient data near the origin, we have constrained the estimates such that they have a maximum of 60 of density-dependent mortality assumed by the models. If there are no observations close to the origin, the Ricker model estimates an initial slope based upon the levels of density-dependent mortality for larger spawner abundance; this often forces a lower estimate than is probably reasonable.

If standardized juvenile survival is above 1 , then the points on Fig. 4 should lie above the replacement line. This occurs for almost every point on the plot. There are a few years for W Greenland, Labrador/NE Newfoundland, and the southern Grand Bank that are on the line.

\section{What is the resilience of the population, i.e. its ability to reproduce and grow at low population sizes?}

The spawner recruitment data (Fig. 4) show that juvenile survival is usually enhanced, not reduced, at low spawners densities. In particular, there is no evidence of depensation, i.e. higher mortality at low population abundance (Myers et al. 1995a). Thus, these populations should be able to recover if fishing mortality is reduced (Pimm 1991).

There is a fear that once cod populations are reduced they will remain low even though fishing mortality is reduced because mortality by predators, e.g. grey seals Halichoerus grypus, will be sufficient to keep the population from growing. This is the 'predator pit' proposed by Southwood \& Comins (1976). An analysis by Myers et al. (1995a) suggests that the predator pit hypothesis is unlikely for cod, or any other gadoid, because mortality does not increase at low abundance. Perhaps the only evidence for the predator pit hypothesis for cod comes from the increase of gadoid species in the North Sea in the 1960s. Dann (1980) hypothesized that this was caused by a reduction in juvenile mortality by adult gadoid predators when they were reduced by fishing.

The best evidence for a recovery is in the Northeast Arctic (i.e. the Barents Sea), where greatly reduced fishing from 1989-1991 (Fig 2) quickly gave a substantial increase in SSB (Jakgbsen 1994). Recruitment of the incoming year classes was good and they were allowed to spawn, which led to the largest SSB in more than 30 yr (Fig. 2).

The situation for the Canadian cod stocks is not so optimistic. To date research surveys show few signs of an increase in recruitment in some of these stocks as a result of the cessation of fishing in 1992 and 1993. The simplest explanation for this is that recruitment is low because SSB has been reduced to record lows for these stocks (Fig. 2). It is clear that stocks do not recover if fishing mortality remains very high. For example, Georges Bank cod has been at a low level for over 
30 yr. The age-structure in these stocks has also been severely reduced, which may reduce the spawning period of these stocks because older cod spawn for a longer time. This should increase recruitment variability because of the reduced probability that the timing of peak larval abundance will match the timing of the peak in plankton biomass (Hutchings \& Myers 1993).

\section{Do catchability, spatial distribution, and fishing mortality change at low population sizes?}

It is widely believed that fisheries for pelagic species are more prone to collapse than fisheries for demersal species (Beverton 1990). Beverton suggested that the reason for this is that in small pelagic fish there is an escalation of catchability (i.e. the ratio of fishing mortality to fishing effort) as population size decreases. Garrod (1988) suggested that such an effect is much weaker for demersal species, such as cod, that do not form tight shoals. We contend that these beliefs should be modified

First, does catchability increase as population size decreases for cod? Gulland (1964) showed that after World War II, when demersal fish (cod, plaice, and sole) were only lightly exploited in the North Sea, catchability was initially high, but declined as dense pockets of fish were fished out. Hutchings \& Myers (1994) and Waiters \& Pearse (1996) demonstrated that catchability in otter trawls for the Labrador/NE Newfoundland stock increased as the population abundance decreased. Swain et al. (1995) found that catchability in otter trawls of young cod (age 4 yr or less) increased at low population sizes, but cod older than age 8 yr were less catchable at low abundance. These studies may be confounded by increases in catchability over time because of improved technology.

Second, does the area occupied by cod decrease as the population declines? Myers \& Cadigan (1995a) demonstrated that the area occupied by cod of the Labrador/Newfoundland stock declined as the population declined. The results of the Swain \& Sinclair (1994) study of the density-dependent change in the area occupied by cod of the southern Gulf of St. Lawrence found that the area containing $95 \%$ of the population decreased as abundance decreased but that the areas of high concentrations did not. Myers \& Stokes (1989) showed that for North Sea cod the area occupied by juveniles (ages 1 to $3 \mathrm{yr}$ ) did not decrease as the population decreased. We conclude that there is evidence for density-dependent changes in some stocks, but overall the evidence is equivocal.

Third, fishing mortality may increase as population sizes decrease. For several of the stocks, fishing mortality increased enormously as the population declined (e.g. Labrador/NE Newfoundland, northern Gulf of St. Lawrence). These high levels of fishing mortality, originally estimated from vitual population analysis (VPAs), have been confirmed by independent markrecapture estimates (Myers et al. 1996a, b). The increase in fishing mortality and effort is clear for many of the cod populations in the North Atlantic.

In conclusion, we know very little about changes in the catchability and geographic distribution of cod at low population sizes. However, it appears that economic pressure favours increases in exploitation rates and effort when populations are reduced to low levels. Unless fishing effort is tightly constrained, it is likely to increase as populations decline.

\section{How did the perception of fishing mortality change over time?}

Instantaneous fishing mortality rate of all Canadian stocks increased suddenly around 1989 to 1992 (Fig. 6). It increased from approximately 0.5 in the mid 1980 s to above 1 for all stocks except southern Grand Bank (Fig. 2). Changes in fishing mortality have shown a very different pattern in the eastern Atlantic and Georges Bank, where the fishing mortality has gradually increased from 0.5 to about 1 for most stocks. The sudden and rapid increase in fishing mortality in the Canadian stocks was unexpected and unpredicted.

How could such a rapid increase occur when the management goal was to maintain fishing mortality at $F_{0.1}$ (which is typically around 0.2 )? It is useful to examine the changes in the perception of fishing mortality over time. Biomass for Canadian cod stocks has been consistently overestimated while fishing mortality has been underestimated (Steele et al. 1992)

This underestimation was recognized as early as 1986 (Steele et al, 1992). There are 2 reasons for this underestimation. First, there is a purely statistical bias that is inherent in the estimation procedures used (Smith \& Gavaris 1993, Myers \& Cadigan 1995b). Second, there was a general tendency to give too much weight to the index of abundance that gave the most optimistic estimate of abundance. In particular, reliance on commercial catch rates in the 1980 s resulted in biases because of increases in harvesting efficiency over time (Hilborn \& Walters 1992, Hutchings \& Myers 1994, Walters \& Maguire 1996).

In the late 1980 s there was a general realization that fishing mortality was much greater than was previously believed. However, there was a general unwillingness to reduce fishing mortality because the shortterm economic consequences were too great (Rivard \& Maguire 1993, Walters \& Maguire 1996). It was decided that, since a fishing mortality of 0.5 had been 


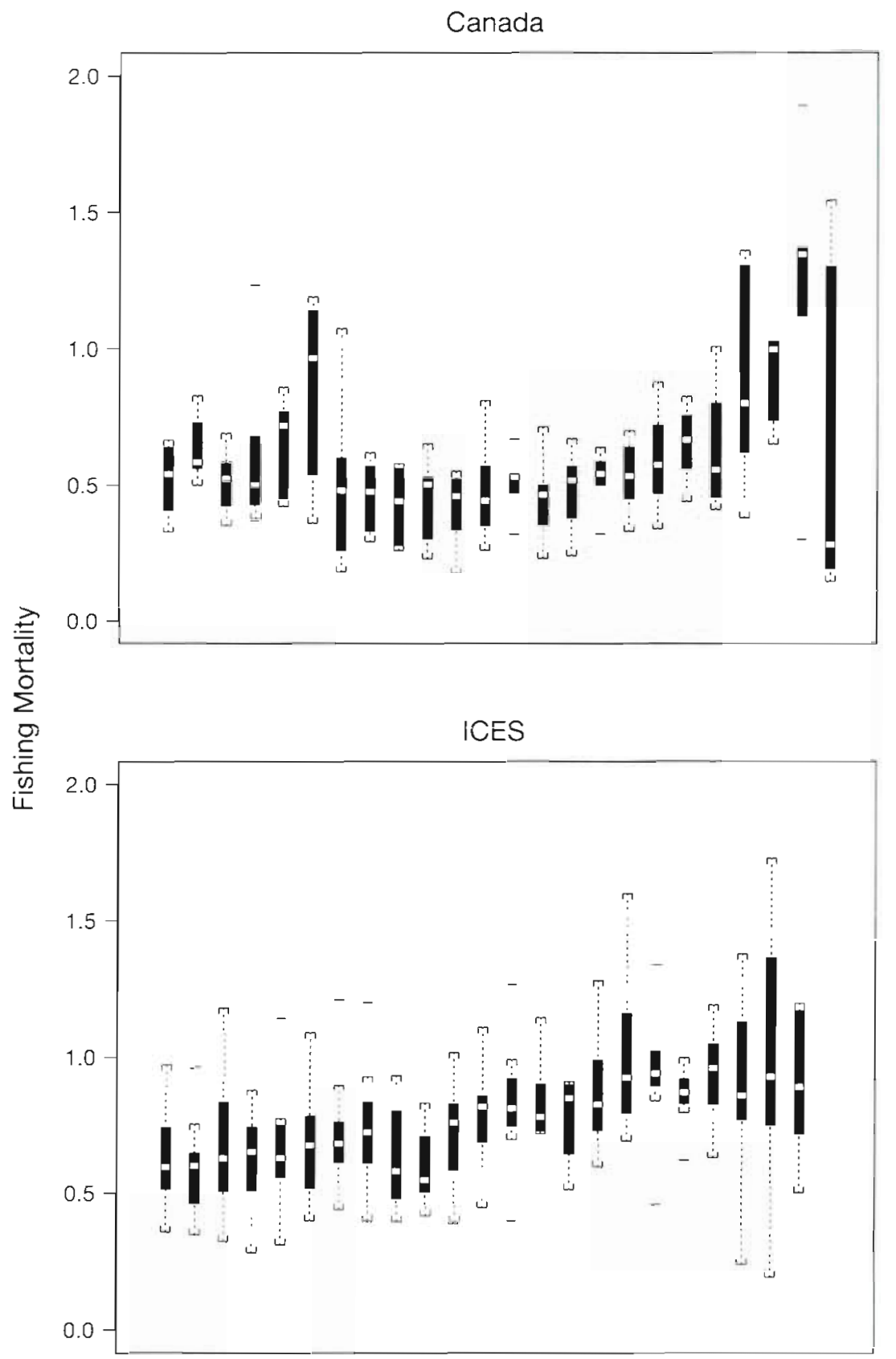

707172737475767778798081828384858687888990919293

Year

Fig. 6. Box and whisker plots (see Fig. 5 for explanation and note that horizontal dashes indicate outliers) of fishing mortality for the IC:ES (Eastern Atlantic) and the Canadian stocks. The very high fishing mortalities of Labrador/NE Newfoundland cod in 1991 and 1992 have been eliminated from the plot to allow better comparisons of the data

sustained in European stocks, that there was no need to reduce fishing mortality quickly. However, quantitative analyses clearly demonstrated that stocks have very low probability of growing under such a high fishing mortality (Rice \& Evans 1986). It was also believed that previous biases in the estimation of population size and fishing mortality had been corrected (Rivard \& Maguire 1993). In retrospect, both reasons for not reducing fishing mortality turned out to be incorrect. Quotas that were believed to induce a fishing mortality of around 0.5 resulted in fishing mortality of greater than 1, and the remaining spawners were greatly reduced. For the Labrador/NE Newfoundland stock, which had been the largest Canadian stock, research surveys showed strong recruitment in the late 1980s. However, the recruits produced by these 1986 and 1987 year classes were caught in unusually high numbers in the early 1990s. The 1990 and 1991 catches of the 1986 year class were the highest numerical catches of 4 and 5 yr olds since 1977 and 1973 , respectively (Bishop et al. 1993). Similarly, the 1990 catch of the 1987 year class was the highest catch of $3 \mathrm{yr}$ olds since 1976. Clearly, the preponderance of small, young cod in the 1990 and 1991 catches was due to the relative absence of older fish.

It is also useful to examine the landings as the populations declined. There was a general tendency to maintain relatively stable catches even when the population was declining (Fig 2). For many stocks the landings did not decline until after there was a large reduction in SSB, e.g. Labrador/NE Newfoundland cod. The inshore landings for this stock actually increased during the period when SSB was declining, due in part to spatial shifts in fixed gear effort (Hutchings \& Myers 1994). More younger fish were landed as the population collapsed (Fig. 7). In the last years of the fishery, almost $90 \%$ of the reported landings were immature fish (cod from this stock mature for the first time at age 6 or $7 \mathrm{yr}$ ). The agespecific pattern of exploitation in 1978 is similar to that in the 1990s. In both cases the stock was overexploited.

For some stocks, landings and SSB decline together, e.g. North Sea. For these stocks, the landings almost entirely depend upon recruitment and the 2 trends represent a relatively stable level of exploitation. For 

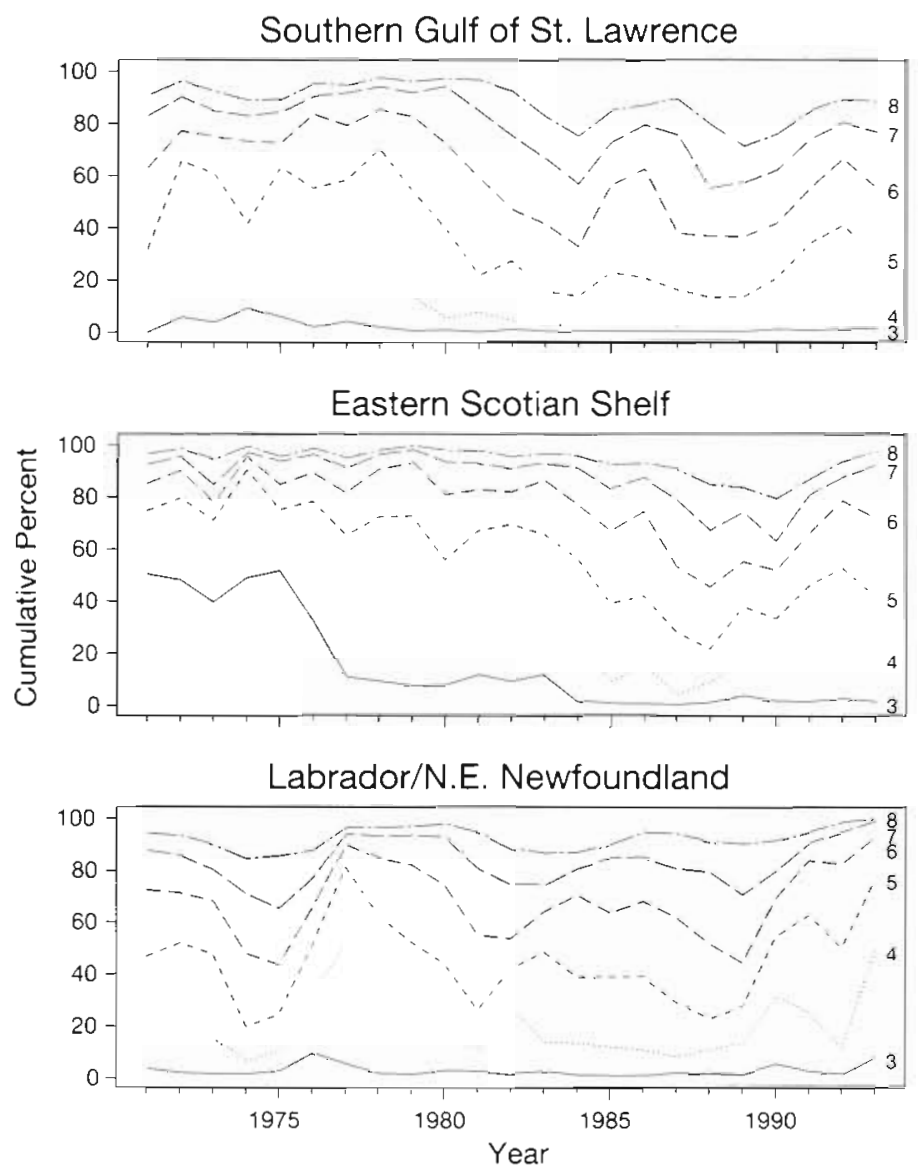

Fig. 7. Age composition of reported landings for the LabradoriNE Newfoundland stock, southern Gulf of St. Lawrence, and eastern Scotian Shelf. Data are shown as cumulative percent, i.e. the line for age 5 yr represents the percentage of reported landings of age $5 \mathrm{yr}$ and under

example, the most common age in the reported catch for North Sea cod has been age 1 or 2 for the last 15 yr. Populations with very high somatic growth rates such as North Sea cod may be protected from commercial extinction largely by their ability to reproduce at an early age, e.g. at age 2 or 3 yr.

An overestimation of abundance and the setting of a quota that is too high will not in itself result in overexploitation; the capacity to remove the fish rapidly is also required. When Canada declared the 200 mile limit in 1977, there was an overinvestment in fishing boats and processing capacity (Angel et al. 1994); this allowed a large quantity of fish to be removed in a very short time.

How does the collapse of cod compare with the collapse of small pelagic fish examined by Beverton?

Beverton (1990) reviewed the collapse of small pelagic marine species, i.e. 5 Atlantic herring Clupea harengus stocks, Peruvian anchoveta Engraulis ringens, Southern African pilchard Sardinops ocellatus, Pacific sardine Sardinops caerulea, Barents Sea capelin Mallotus villosus, and Pacific mackerel Scomber japonicus. The magnitude of the decline in the cod stocks is usually less than the decline in the 10 small pelagic stocks studied by Beverton (1990). In only 3 cases was the extent of the decline (fraction of the minimum stock size to that of the peak) of small pelagic fish less than the maximum collapse for any cod stocks. The median ratio of the SSB at the collapse to the peak was $1 / 100$ in the small pelagic fish.

Beverton (1990) concluded that fishing was the main cause of the collapse in most but not all the small pelagic stocks he studied. He suggested that the main cause of the overfishing was an escalation of catchability as stock size decreased, caused by the shoaling habit of the species he studied. There appeared to be a greater effect of environmental variability in juvenile survival for small pelagic fish than cod. Beverton suggested that juvenile survival alone would have caused the collapse of one stock, i.e. Icelandic springspawning herring

\section{CONCLUSION}

There is much to be learned from the history of cod in the North Atlantic. Although cod has enormous resistance to overexploitation, it has been reduced to near commercial extinction in much of its range. The prime factor in this decline is almost always fishing; interannual variation in juvenile survival, usually attributed to environmental variation, is not generally responsible for the decline of the species.

Even when spawners are reduced to very low levels, some recruitment can still be maintained because juvenile survival increases at low abundance (Myers \& Cadigan 1993a, b). However, recruitment at low spawner abundance is at greatly reduced level for cod and other fish species (Myers \& Barrowman 1996). Unfortunately, the ability to produce recruits is largely counteracted by the ability of modern fishing fleets to catch fish efficiently at low densities. This is often augmented by increased fishing effort at low densities (Hutchings \& Myers 1994).

There has been a notable lack of success in finding environmental links to recruitment that have held up when reexamined using independent data (Shepherd et al. 1984, Drinkwater \& Myers 1987, Myers \& Drinkwater 1989, Hutchings \& Myers 1994, Myers et al. 1994b, 1995d). Furthermore, Walters \& Collie (1988), Bradford (1992) and Mertz \& Myers (1995) have con- 
vincingly argued that environmental correlates are unlikely to be useful in predicting recruitment with sufficient accuracy to be useful in management. This suggests that the strong emphasis on research into environmental causes of recruitment variability should be reconsidered.

The pattern of decline of cod has not been the same throughout the North Atlantic. Fishing mortality increased relatively slowly through the 1970 s and 1980 s in the Eastern Atlantic, while off the East Coast of Canada there was a very rapid rise in fishing mortality in the late 1980s and early 1990s which followed several years of gradual increase. The consequences of this extraordinary rise of fishing mortality in the Northwest Atlantic should be viewed as a major ecological and economic disaster. For each of the stocks that collapsed, fishing mortality was underestimated in assessments and there was a great excess in fishing capacity. Each collapse followed a similar pattern: the rise in fishing mortality was associated with a reduction in age structure, i.e. old fish were eliminated, followed by a rapid increase in fishing mortality and an increase in discarding of young fish (Myers et al. 1996c).
The perception that cod stocks are resistant to overexploitation should be changed (Walters \& Maguire 1996). We have demonstrated that fishing mortality can increase very rapidly for codi it is thus imperative to be conservative in the setting of quotas. It is clear that in Canada the abundance was overestimated before the collapses in the 6 stocks occurred. In each of these cases the commercial fishery was able to catch the quota, which resulted in large, rapid increases in fishing mortality. If a large overcapacity in the fishing industry is maintained, then an overestimate of abundance in 1 or 2 yr may cause a population to be nearly eliminated

Ultimately, the lesson we must learn from the collapse of the cod stocks in the North Atlantic is that spawning stocks must be conserved to allow for future recruitment. This has proven to be very difficult.

Acknowledgements. We thank the Northern Cod Science program for financial assistance. We thank B. Dempson, R. L. Haedrich, J. Hoenig, G. Mertz, D. Stansbury, and K. Stokes for helptul suggestions.

Appendix 1. Data

The data we used are estimates obtained from assessments of the stocks by international (the Northwest Atlantic Fisheries Organization-NAFO, or the Intermational Council for the Exploration of the Sea-ICES) or national organizations (Department of Fisheries and Oceans in Canada and the National Marine Fisheries Service in the USA). We used all assessments that were completed by August of 1993 . Population numbers and fishing mortality were estimated using sequential population analysis (SPA) of commercial catch at age data for most marine stocks. SPA techniques include virtual population analysis (VPA $A_{i}$ Gulland 1965), cohort analysis (Pope 1972), and related methods which reconstruct population size from catch at age data. The population dynamics model assumed for these methods once a fish has entered the fishery is

$$
N_{y, l, a+1}=N_{y, d} \mathrm{e}^{-M_{\alpha}-F_{y} a}
$$

where $N_{y}$ is the number of fish at the beginning of year $y$ at age $a, M_{d}$ is ndtural mortality at age $a$ and $F_{v, d}$ is the fishing mortality at age a in year $y$. See Hilborn \& Walters (1992, Chapters 10 and 11) for a description of the methods used to reconstruct the population history. Briefly, the commercial catch at age is combined with estimates from research surveys and commercial catch rates to estimate the numbers at age in the final year, and to reconstruct previous numbers at age under the assumption that commercial catch at age is known without error and that natural mortal.ity at age is known and constant.

The stock boundaries in the North Atlantic generally follow those of NAFO or ICES. We have summarized the available data on 20 cod stocks in the North Atlantic (Fig. 2)
There are 3 minor stocks that are not included in the comparative analysis: Flemish Cap, Gulf of Maine, and the English Channel. There are no reliable catch data for the Flemish Cap stock (NAFO 3M). The assessment of the English Channel stock (ICES VIId) by SPA was rejected by the last assessment review (ICES 1994b) and the data series is limited. The time series of data for the Skagerrak (ICES IIIa) and Gulf of Maine (NAFO 5Y) are not included in the comparative analysis because the time series is too short (less than $10 \mathrm{yr}$ ).

When available, 3 reference levels of fishing mortality that are used by management agencies are indicated with dashed horizontal lines in Fig. 2; they are

$F_{\text {max }}$, the fishing mortality that gives maximum yield per recruit, i.e. the fishing mortality for which the derivative of yield per recruit with respect to fishing mortality is zero.

$F_{0}$, the fishing mortality for which the derivative of yield per recruit with respect to fishing mortality is 0.1

$F_{\text {med, }}$ the fishing mortality which corresponds to the median observed level of recruitment per spawner.

The ages over which fishing mortality is averaged are given in Table 1

In calculating SSB we have assumed that the proportion mature over time is constant with age. This will allow an index of abundance to be compared over time. For some stocks, this will overestimate the number of spawners in the past because of a decrease in age at maturity with time 


\section{LITERATURE CITED}

Angel JR, Burke DL, O'Boyle RN, Peacock FG, Sinclair M, Zwanenburg KCT (1994) Report of the workshop on Scotia-Fundy groundfish management from 1977 to 1993. Can Tech Rep Fish Aquat Sci No. 1979

Atkinson DB. Bennett B (1994) Proceedings of a northern cod workshop held in St. John's, Newfoundland, Canada January 27-29. Can Tech Rep Fish Aquat Sci No. 1999

Beverton RJH (1990) Small marine pelagic fish and the threat of fishing; are they endangered? J Fish Biol 37(Suppl): $5-16$

Bishop CA, Murphy EF, Davis MB, Baird JW, Rose GA (1993) An assessment of the cod stock in NAFO Divisions $2 J+3 K L$. NAFO SCR Doc 93/86, Ser No N2271:1-51

Bradford MJ (1992) Precision of recruitment predictions from early life stages of marine fishes. Fish Bull 90:439-453

Cushing DH (1982) Climate and fisheries. Academic Press, London

Dann $N$ (1980) A review of replacement of depleted stocks by other species and the mechanisms underlying such replacement. Rapp PV Réun Cons Int Explor Mer 177. $405-421$

Dickson RR, Brander KM (1993) Effects of a changing windfield on cod stocks of the North Atlantic. Fish Oceanogr $2: 124-153$

Drinkwater KF, Myers RA (1987) Testing predictions of marine fish and shellfish landings from environmental variables. Can J Fish Aquat Sci 44:1568-1573

Gabriel W, Sissenwine MP, Overholtz WJ (1989) Analysis of spawning stock biomass per recruit: an example for Georges Bank haddock. N Am J Fish Manage 9:383-391

Garrod DJ (1988) North Atlantic cod: fisheries and management to 1986. In: Gulland JA (ed) Fish population dynamics: the implications for fishery management. John Wiley \& Sons, New York, p 185-218

Garrod DJ, Colebrook JM (1978) Biological effects of variability in the north Atlantic Ocean. Rapp PV Réun Cons Int Explor Mer 173:128-144

Goodyear CP (1977) Assessing the impact of power plant mortality on the compensatory reserve of fish populations. In: Van Winkel $W$ (ed) Proceedings of the conference on assessing the effects of power plant induced mortality on fish populations. Pergamon Press, New York, p 186-195

Gulland JA (1964) The reliability of catch per unit effort as a measure of abundance of the North Sea trawl fisheries. In: Gulland JA (ed) On the measurement of abundance of fish stocks. Rapp PV Réun Cons Int Explor Mer 155:98-102

Gulland JA (1965) Estimation of mortality rates. Annex to Rep. Arctic Fish. Working Group, CM-ICES 1965(3):71-79

Hilborn R. Walters CJ (1992) Quantitative fisheries stock assessment: choice, dynamics and uncertainty. Chapman \& Hall, New York

Hoaglin DC, Mosteller F, Tukey JW (eds) (1983) Understanding robust and exploratory data analysis. Wiley, New York

Hutchings JA, Myers RA (1993) The effect of age on the seasonality of maturation and spawning of Atlantic cod, Gadus morhua. Can J Fish Aquat Sci 50:2468-2474

Hutchings JA, Myers RA (1994) What can be learned from the collapse of a renewable resource? Atlantic cod, Gadus morhua, of Newfoundland and Labrador. Can J Fish Aquat Sci 51:2126-2146

ICES (1994a) Cod and climate change. ICES Mar Sci Symp 198

ICES (1994b) Report of the working group on the assessment of southern shelf demersal stocks. CM-ICES 1994(3)

Jakøbsen I (1994) Management of the northeast Arctic cod- past, present, and future. In: Kruse G, Eggers DM, Marasco RJ, Pautzke C, Quinn TJ (eds) International symposium of management strategies for exploited fish populations. Alaska Sea Grant College Program, Fairbanks, p 321-338

Mace PM (1994) Relationships between common biological reference points used as thresholds and targets of fisheries management strategies. Can J Fish Aquat Sci 51:110-122

Mace PM, Sissenwine MP (1993) How much spawning per recruit is enough? In: Smith SJ, Hunt JJ, Rivard D (eds) Risk evaluation and biological reference points for fisheries management. Can Spec Publ Fish Aquat Sci 120 101-118

Mann KH, Drinkwater KF (1994) Environmental influences of fish and shellfish production in the Northwest Atlantic Environ Rev 2:16-32

Mertz G, Myers RA (1995) Estimating the predictability of recruitment. Fish Bull 93:656-664

Murawski SA, Maguire JJ, Mayo RK, Serchuk FM (1996) Groundfish stocks and the fishing industry. Am Fish Soc Spec Publ (in press)

Myers RA, Barrowman NJ (1996) Is fish recruitment related to spawner abundance? Fish Bull (in press)

Myers RA, Barrowman NJ, Hoenig J, Qu Z (1996a) The collapse of cod in Eastern Canada: the evidence from tagging data. ICES J Mar Sci 53:629-640

Myers RA, Barrowman NJ, Hutchings JA (1996b) Exploitation of inshore stocks of Newfoundland cod since 1948 as estimated from mark-recapture data. Can J Fish Aquat Sci (in press)

Myers RA, Barrowman NJ, Hutchings JA, Rosenberg AA (1995a) Population dynamics of exploited fish stocks at low population levels. Science 269:1106-1108

Myers RA, Barrowman NJ, Thompson KR (1995b) Synchrony of recruitment across the North Atlantic: an update or now you see it, now you don't. ICES J Mar Sci 52:103-110

Myers RA, Bridson J, Barrowman NJ (1995c) Summary of worldwide stock and recruitment data. Can Tech Rep Fish Aquat Sci 2024

Myers RA, Cadigan NG (1993a) Density-dependent juvenile mortality in marine demersal fish. Can J Fish Aquat Sci 50 $1576-1590$

Myers RA, Cadigan NG (1993b) Is juvenile natural mortality in marine demersal fish variable? Can J Fish Aquat Sci 50: $1591-1598$

Myers RA, Cadigan NG (1995a) Was an increase in natural mortality responsible for the collapse of northern cod? Can J Fish Aquat Sci 52:1274-1285

Myers RA, Cadigan NG (1995b) Statistical models for catch at age data with correlated errors. Can J Fish Aquat Sci 52:1265-1273

Myers RA, Drinkwater KF (1989) The influence of Gult Stream warm core rings on recruitment of fish in the Northwest Atlantic. J Mar Res 47:635-656

Myers RA, Hutchings JA, Barrowman NJ (1996c) Why do fish stocks collapse. Ecol Appl (in press)

Myers RA, Mertz G, Barrowman NJ (1995d) Spatial scales of variability in cod recruitment in the North A.tlantic. Can J Fish Aquat Sci 52:1849-1862

Myers RA, Stokes K (1989) Density-dependent habitat utilization of groundfish and the improvement of research surveys. CM-ICES 1989/D:15

Pimm SL (1991) The balance of nature. The University of Chicago Press, Chicago

Pope JG (1972) An investigation of the accuracy of virtual population analysis using cohort analysis. ICNAF Res Bull 9:65-74 
Rice J, Evans G (1986) Re-examining target spawning biomass for the cod stock in NAFO Divisions $2 \mathrm{~J}+3 \mathrm{KL}$. NAFO SCR Doc 86/30, Ser No. N11 44:1-5

Ricker WE (1954) Stock and recruitment. J Fish Res Bd Can II(5):559-623

Rivard D, Maguire JJ (1993) Reference points for fisheries management: the eastern Canadian experience. In: Smith SJ, Hunt JJ, Rivard D (eds) Risk evaluation and biological reference points for fisheries management. Can Spec Publ Fish Aquat Sci 120:31-57

Royama T (1992) Analytical population dynamics. Chapman Hall, London

Shepherd JG, Pope JG, Cousens RD (1984) Variations in fish stocks and hypotheses concerning their links with climate. Rapp PV Réun Cons Int Explor Mer 185:255-267

Smith SJ, Gavaris S (1993) Evaluating the accuracy of projected catch estimates from sequential population analysis and trawl survey abundance estimates. In: Smith SJ, Hunt JJ. Rivard D (eds) Risk evaluation and biological reference points for fisheries management. Can Spec Publ Fish Aquat Sci 120:163-172

Southwood TRE, Comins HN (1976) A synoptic ponulation model. J Anim Ecol 46:949-965

Steele DH, Andersen R, Green JM (1992) The managed commercial annihilation of northern cod. Newfoundland Stud 8:34-68

This review was presented by R. L. Haedrich (Senior Editorial Advisor), St. John's, Newfoundland, Canada
Swain DP, Nielsen GA, Sinclair AF, Chouinard GA (1995) Changes in catchability of Atlantic cod (Gadus morhua) to an otter-trawl fishery and research survey in the southern Gulf of St. Lawrence. ICES J Mar Sci 51:493-504

Swain DP, Sinclair AF (1994) Fish distribution and catchability - what is the appropriate measure of distribution. Can J Fish Aquat Sci 51:1046-1054

Templeman W (1972) Year-class success in some North Atlantic stocks of cod and haddock. Int Comm Northwest Atl Fish Special Publ 8:223-239

Walsh SJ, Brodie WB, Bishop CA, Murphy EF (1995) Fishing on juvenile groundfish nurseries on the Grand Bank: a discussion of technical measures of conservation. In: Shackell NL, Willison JHM, Lien J (eds) Marine protected areas and sustainable fisheries. SAMPAA, Centre for Conservation Biology, Acadia University, Wolfville, Nova Scotia, p $54-73$

Walters CJ, Collie JS (1988) Is research on environmental factors useful to fisheries management? Can J Fish Aquat Sci $45: 1848-1854$

Walters CJ, Maguire JJ (1996) Lessons for stock assessment from the northern cod collapse. Rev Fish Biol Fish (in press)

Walters CJ, Pearse PH (1996) Stock information requirements for quota management systems in commercial fisheries Rev Fish Biol Fish 6:21-42

Manuscript first received: January 30, 1995

Revised version accepted: March 12, 1996 